COSTA, D.N.M. et al. Aspectos clínicos do flegmão intersticial bovino. PUBVET, Londrina, V. 8, N. 10, Ed. 259, Art. 1721, Maio, 2014.

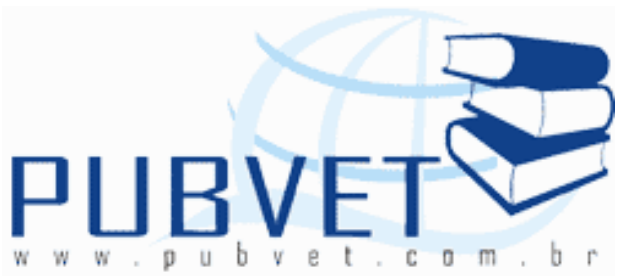

PUBVET, Publicações em Medicina Veterinária e Zootecnia.

\title{
Aspectos clínicos do flegmão intersticial bovino
}

Deyse Naira Mascarenhas Costa ${ }^{1}$; Hiocilma Perla dos Santos Santos ${ }^{2}$; Anderson Sobral Bezerra ${ }^{1}$; Catarina Rafaela Alves da Silva²; Rosvaldo Duarte Barbosa ${ }^{3}$ Francisco Solano Feitosa ${ }^{3}$; Severino Vicente da Silva ${ }^{3}$

${ }^{1}$ Médico Veterinário Autônomo

2 Doutorando em Ciência Animal - UFPI

3 Professor Doutor Associado do Departamento de Clínica e Cirurgia Animal UFPI

\section{Resumo}

A claudicação em rebanhos leiteiros tem-se caracterizada como uma afecção bastante prevalente e onerosa para os criadores. Problemas reprodutivos, mastite e afecções podais são as afeç̧ões mais importantes no panorama da pecuária leiteira. Neste contexto salienta-se que a incidência deste problema é bastante variável, alcançando percentuais entorno de 5 a $120 \%$ anualmente. Este trabalho relata o caso de uma fêmea bovina da raça Girolanda, atendida na Clínica de Grandes Animais (Hospital Veterinário Universitário-UFPI), apresentando sinais clínicos de desconforto durante a locomoção. As técnicas de diagnóstico são descritas. O animal após trinta dias estava com a saúde restabelecida. O caso serve de alerta e orientação para a importância dos controles profilático e terapêutico dentro de rebanhos leiteiros como forma de promover a erradicação das lesões podais em bovinos.

Palavras-chave: Pecuária, Bovinos, lesões podais, flegmão interdigital 
COSTA, D.N.M. et al. Aspectos clínicos do flegmão intersticial bovino. PUBVET, Londrina, V. 8, N. 10, Ed. 259, Art. 1721, Maio, 2014.

\section{Clinical aspects of veal phlegmon intersticial}

\section{Abstract}

Lameness in dairy cattle has been characterized as a disease quite prevalent and costly for developers. Reproductive problems, mastitis and foot problems are the most important diseases in the panorama of dairy farming. In this context it is noted that the incidence of this problem is quite variable, percentage reaching around $5-120 \%$ annually. This paper reports the case of a female bovine breed Girolanda, attended the Large Animal Clinic (University Veterinary Hospital-UFPI), clinical signs of discomfort during locomotion. The diagnostic techniques are described. Thirty days after the animal was restored to health. The case serves as a warning and guidance to the importance of prophylactic and therapeutic controls within dairy herds in order to promote the eradication of foot lesions in cattle.

Keywords: Livestock, cattle, foot lesions, interdigital phlegmon

\section{REVISÃO DE LITERATURA}

Os pesquisadores, geneticistas e criadores ao longo dos anos intensificaram as pesquisas acerca do melhoramento genético de bovinos leiteiros. A partir destes trabalhos obteve-se mudanças significativas referentes a determinadas características desses animais como, por exemplo, maior capacidade digestiva, maior desenvolvimento da glândula mamária, melhoramento da capacidade reprodutiva e aumento da produção de leite. Porém esse rápido e eficiente melhoramento genético não promoveu melhoras relativas aos membros locomotores e principalmente nos cascos (BORGES et al.,1992).

O aumento da demanda no mercado por leite e carne bovina favoreceu à intensificação dos sistemas de produção dos rebanhos e para torná-los mais produtivos,optou-se por uma maior concentração de animais por área e como consequência houve aumento no volume de dejetos, maior umidade, grandes dificuldades de manejo e menor higiene (GOGOI et al.,1981;COOK, 2002). 
COSTA, D.N.M. et al. Aspectos clínicos do flegmão intersticial bovino. PUBVET, Londrina, V. 8, N. 10, Ed. 259, Art. 1721, Maio, 2014.

Os problemas relacionados às afecções dos pés dos bovinos adquiriram importância crescente na bovinocultura tornando-se um dos principais entraves econômicos ao seu desenvolvimento, juntamente com os problemas da glândula mamária e os reprodutivos(SOUZA, 2002).

O flegmão interdigital é um processo inflamatório agudo difuso da pele interdigital caracterizado por hipertermia local, hiperemia, edema, aumento de volume acentuado e dor, levando à manqueira grave. O principal agente envolvido é o Fusobacterium necrophorum, podendo estar associado a outros agentes patogênicos. Acomete animais de qualquer idade, sendo mais prevalente em vacas leiteiras mantidas em condições ambientais de umidade elevada e higiene precária, sendo as vacas primíparas as mais susceptíveis. Traumatismos resultantes da penetração de pregos, paus, arames e pedras são fatores predisponentes (NICOLETTI, 2004).

O objetivo deste trabalho é relatar um caso de flegmão interdigital bovino em fêmea bovina, que apesar de ser de ocorrência comum, as formas de tratamento e os resultados são pouco discutidos na literatura nacional. Além de chamar a atenção de criadores e veterinários para melhoria das condições de higiene estabelecidas nas fazendas bovinas leiteiras.

\section{DESCRIÇÃO DO CASO}

Uma bezerra da raça Girolanda, com seis meses de idade, pesando $100 \mathrm{~kg}$, foi atendida na Clínica de Grandes Animais-UFPI. À inspeção verificou-se que o animal apresentava aumento de volume na extremidade distal do membro posterior direito, lesão necrótica, presença do secreção de odor fétido, coloração escura e claudicação no membro posterior direito. A bezerra era mantido em sistema de criação intensivo, sendo alimentado com Mombaça (Panicum maximum), leite e concentrado. Ao exame físico aferiu-se a temperatura retal em torno de $39,4^{\circ} \mathrm{C}$, frequência respiratória de 22 movimentos/minuto, frequência cardíaca igual a 54 batimentos/minuto, motilidade ruminal normal e mucosas oculares e oral normocoradas (figura 1 ) 
COSTA, D.N.M. et al. Aspectos clínicos do flegmão intersticial bovino. PUBVET, Londrina, V. 8, N. 10, Ed. 259, Art. 1721, Maio, 2014.

O diagnóstico realizou-se pelos sinais clínicos, histórico e lesões características confirmando tratar-se de flegmão interdigital (podridão dos cascos). O tratamento consistiu na lavagem da região afetada, antissepsia com álcool iodado e posterior retirada do tecido necrosado. Realizou-se a anestesia infiltrativa no sentido dorso plantar, com lidocaína a $2 \%$ sem vaso constritor, na dose de $10 \mathrm{ml}$. Após anestesia, procedeu-se a retirado do tecido necrosado e em seguida cauterização com ferro quente. Institui-se a aplicação tópica de sulfato de cobre a $10 \%$, nitrofurazona e óxido de zinco. Tal procedimento foi realizado diariamente até completa recuperação do membro.

Como tratamento parenteral, foi administrado Dexametasona $2 \mathrm{mg}$ (10mg/IM/BID) e Enrofloxacina $100 \mathrm{mg}(2,5 \mathrm{mg} / \mathrm{kg} / \mathrm{SID} / \mathrm{SC})$ durante três dias consecutivos.

O animal foi mantido em baia limpa, seca para evitar uma nova contaminação na região acometida. Passados trinta dias, a bezerra estava clinicamente recuperada.

\section{DISCUSSÃO E CONCLUSÃO}

A bactéria anaeróbica gram-negativa Fusobacterium necrophorum é habitante normal do rúmen e intestino de bovinos e ovinos, porém pode em determinados momentos, agente oportunista dos cascos de ambas espécies. Sendo o agente mais comumente isolado no flegmão interdigital. Tal bactéria secreta uma potente exotoxina com propriedade hemolítica, causando celulite necrótica na pele interdigital (SILVA, 1997; SILVA et al.,2001;NICOLETTI, 2004).

Fusobacterium necrophorum e a maioria das bactérias isoladas no flegmão são sensíveis a vários antibióticos e sulfonamidas, entretanto é fundamental que o tratamento seja iniciado imediatamente a observação do sinais clínicos, de modo a garantir resultado favorável e evitar complicações secundárias. Em casos avançados deve ser realizada a remoção do tecido necrosado e em seguida aplicação tópica de adstringentes- sulfato de cobre ou anti-sépticos- 
COSTA, D.N.M. et al. Aspectos clínicos do flegmão intersticial bovino. PUBVET, Londrina, V. 8, N. 10, Ed. 259, Art. 1721, Maio, 2014.

sob penso protetor, e os curativos devem ser trocados diariamente (NICOLETTI, 2004).

Previne- se a doença ao realizar limpeza e drenagem adequadas de áreas onde ocorre concentração de animais (bebedouros, cochos, corredores de passagem, estábulos, baias etc). Instalação de pedilúvio com sulfato de cobre ( $5 \%$ ou $10 \%$ ) ou sulfato de zinco a $5 \%$. Em caso de animal acometido, isolá-lo para tratamento e mantê-lo em local limpo e seco. Tais medidas são suficientes e necessárias para profilaxia das afecções dos membros de bovinos, garantindo o sucesso da pecuária leiteira e diminuindo os entraves para seu desenvolvimento.

A partir da melhora clínica do estado geral e do membro afetado da bezerra conclui-se que o tratamento preconizado foi eficiente para a recuperação do animal.

\section{REFERÊNCIAS}

BORGES, J.R.J.; PITOMBO, C.A.; MCDEREMONT, J.J. Incidência de afecções podais em bovinos leiteiros submetidos a diferentes sistemas de manejo. Arq. Esc. Med. Vet. UFBA, v.15, p.3242, 1992.

COOK, N.B. Casco: doenças, custos, fatores de risco e prevenção. Novos enfoques na produção de bovinos, Conapec Jr, Uberlândia, p. 8-14, 2002.

GOGOI, S.N.; NIGAN, J.M.; SINGH, A.P. et al. Incidences of foot disorders in cattle. Mod.Vet. Pract., v.62, n.12, p.941-945, 1981.

SILVA, C. A. Identificação e isolamento do Dichelobacter nododus e do Fusobacterium necrophorum de bovinos portadores de pododermatite, relações com etiopatogenia, dados edafoclimáticos e avaliação de tratamento.1997, 81 f. Dissertação- mestrado em Medicina Veterinária- Escola de Veterinária, Universidade Federal do Goiás, Goiás.

SILVA, L. A. F. Características clínicas e epidemiológicas das enfermidades podais em vacas lactantes do município de Orizona- GO. Ciência Animal Brasileira, v.22, p. 119-126, 2001.

SOUZA, R.C. Perfil epidemiológico e clínico das afecções podais em vacas nas bacias leiteiras de Belo Horizonte e Pedro Leopoldo. 2002, 72 f. Dissertação -mestrado em Ciência Animal- Escola de Veterinária da Universidade Federal de Minas Gerais, Belo Horizonte. 